\title{
Temporal and Spatial Expression of Podocyte-Associated Molecules Are Accompanied by Proteinuria in IgA Nephropathy Rat Model
}

\author{
H.-Y. LU ${ }^{1}$, L.-Z. CHEN ${ }^{1}$, X.-Y. JIANG ${ }^{1}$, Y. MO ${ }^{1}$, Y.-H. LING ${ }^{1}$, L.-Z. SUN ${ }^{1}$ \\ ${ }^{1}$ Department of Pediatrics, The First Affiliated Hospital of Sun Yat-sen University, Guangzhou, \\ P.R. China
}

Received April 26, 2012

Accepted August 23, 2012

On-line November 22, 2012

\section{Summary}

We used a rat model to assess the role of nephrin, podocin, and desmin in the pathogenesis of IgA nephropathy (IgAN). A rat IgAN model was established by administration of $\mathrm{BSA}, \mathrm{CCl}_{4}$, and lipopolysaccharide (LPS) and compared with healthy control rats. Urinary protein, urine red blood cells, and biochemical parameters were measured for 12 weeks. Renal morphology and ultrastructure were examined by light and electron microscopy. Immunofluorescence was used to assess IgA deposition in the glomeruli and to measure expression of nephrin, podocin, and desmin. Real-time quantitative PCR was used to measure expression of nephrin, podocin, and desmin mRNAs. IgAN rats developed proteinuria at week- 6 and this worsened over time. Pathological changes were evident under light microscopy at week-8 and under electron microscopy at week-4. Immunofluorescence analysis showed deposition of IgA in the kidneys of IgAN rats, but not control rats. IgAN rats had increased expression of glomerular podocin, nephrin, and desmin mRNAs and proteins at week-4. The expression of nephrin, podocin and desmin proteins and the expression of podocin and desmin mRNAs preceded the increase in urinary protein. Taken together, our study of a rat model of IgAN indicates that changes in the expression and distribution of nephrin, podocin, and desmin precede and may cause foot process fusion and proteinuria.
\end{abstract}

\section{Key words}

IgA nephropathy • Proteinuria • Podocyte • Nephrin • Podocin • Desmin

\section{Corresponding author}

Xiao-Yun Jiang, Department of Pediatrics, The First Affiliated Hospital of Sun Yat-sen University, No 58, 2nd Zhong Shan Road,
Guangzhou 510080, China. Fax: 0086-020-87750632. E-mail: xyjiang-3208@163.com

\section{Introduction}

Immunoglobulin A nephropathy (IgAN) is characterized by abnormal deposition of $\operatorname{IgA}$ in the renal glomeruli, and is the most common primary glomerulonephritis (Cai and Chen 2009, Kiryluk et al. 2010). IgAN patients with proteinuria are generally considered to have increased risk for progression to chronic kidney disease (CKD) and renal failure (Barratt and Feehally 2005). Although most IgAN patients develop proteinuria, remission of proteinuria is associated with improved prognosis (Reich et al. 2007). Thus, slowing the progression of IgAN may help to control the development of severe proteinuria. The pathogenesis of proteinuria in IgAN is largely unknown. Elucidation of the pathogenesis of proteinuria in $\operatorname{IgAN}$ may help to identify therapeutic targets and allow prompt treatment, thereby delaying the progression to CKD. Therefore, several suitable animal models of IAGN have been established in order to examine the initiation and progression of this disease (Rifai et al. 1979, Emancipator 2011).

Recent studies of hereditary renal diseases in humans and of experimentally induced renal diseases in animals have indicated that numerous proteins produced by the podocytes are critical for maintenance of the structure and function of the slit diaphragm (SD), a region of the foot processes of podocytes through which blood is filtered. Disruption of the SD may allow passage of large molecules into the urine (Mundel and Shankland 
2002, Lai et al. 2009). These podocyte-associated proteins include nephrin, podocin, and desmin. However, previous studies of the relationship between $\operatorname{IgAN}$ and nephrin, podocin, and desmin have produced conflicting results (Gagliardini et al. 2003, Koop et al. 2003, Szeto et al. 2005, Mao et al. 2006). Thus, it is necessary to clarify the dynamic changes in these proteins during the course of IgAN and the roles of these proteins in IgAN proteinuria.

In this study, we focused on three proteins that appear to have important roles in IAGN: nephrin, podocin, and desmin. Mundel and Shankland (2002) classified podocyte-related molecules into four groups: (i) slit diaphragm complex proteins, including nephrin (a $135 \mathrm{kDa}$ transmembrane glycoprotein in the immunoglobulin adhesion molecule superfamily) and podocin (a $42 \mathrm{kDa}$ transmembrane protein in the stomatin family); (ii) podocyte cytoskeletal proteins, including desmin (a $53 \mathrm{kDa}$ cytoskeletal intermediate filament protein that is a maker of podocyte injury); (iii) basement membrane-podocyte junction proteins; and (iv) podocyte top membrane proteins.

In the present study, we established a rat model of IgAN to investigate the dynamic changes in the distribution of nephrin, podocin, and desmin in the glomeruli, assess the association of these proteins with IgAN proteinuria, and elucidate the pathogenesis of proteinuria in IgAN.

\section{Materials and Methods}

\section{Animals and grouping}

Ninety-six 6-week-old male Sprague-Dawley rats (specific pathogen free) weighing $150 \pm 10 \mathrm{~g}$ were purchased from the Experimental Animal Center of the Medical College of Sun Yat-Sen University (Guangzhou, China). Rats were given ad libitum access to food and water. All rats were active and had glossy hair before the start of the experiments.

\section{Establishment of IgAN model}

The rats were randomly assigned to a control group $(n=48)$ and an IgAN group $(n=48)$. The rat IgAN model was established by administration of bovine serum albumin (BSA), lipopolysaccharide (LPS), and carbon tetrachloride $\left(\mathrm{CCl}_{4}\right)$ as reported previously (Emancipator 2001, Tang et al. 2006, Peng and Liu 2008), with slight modification (Fig. 1). In brief, immunogen BSA (MBCHEM, USA) was intragastrically administered at $400 \mathrm{mg} / \mathrm{kg}$ once every two days for 8 consecutive weeks and $0.1 \mathrm{ml}$ of $\mathrm{CCl}_{4}$ in $0.3 \mathrm{ml}$ of castor oil was given once weekly for 9 weeks. At the $6^{\text {th }}$ week, $0.05 \mathrm{mg}$ of LPS (Sigma, USA) was injected through the tail vein. For the control group, $4 \mathrm{ml} / \mathrm{kg}$ distilled water was used to replace the BSA, $0.4 \mathrm{ml}$ of castor oil was used to replace castor oil and $\mathrm{CCl}_{4}$, and saline was used to replace LPS at the $6^{\text {th }}$ week. The administration methods were the same as in the model group.

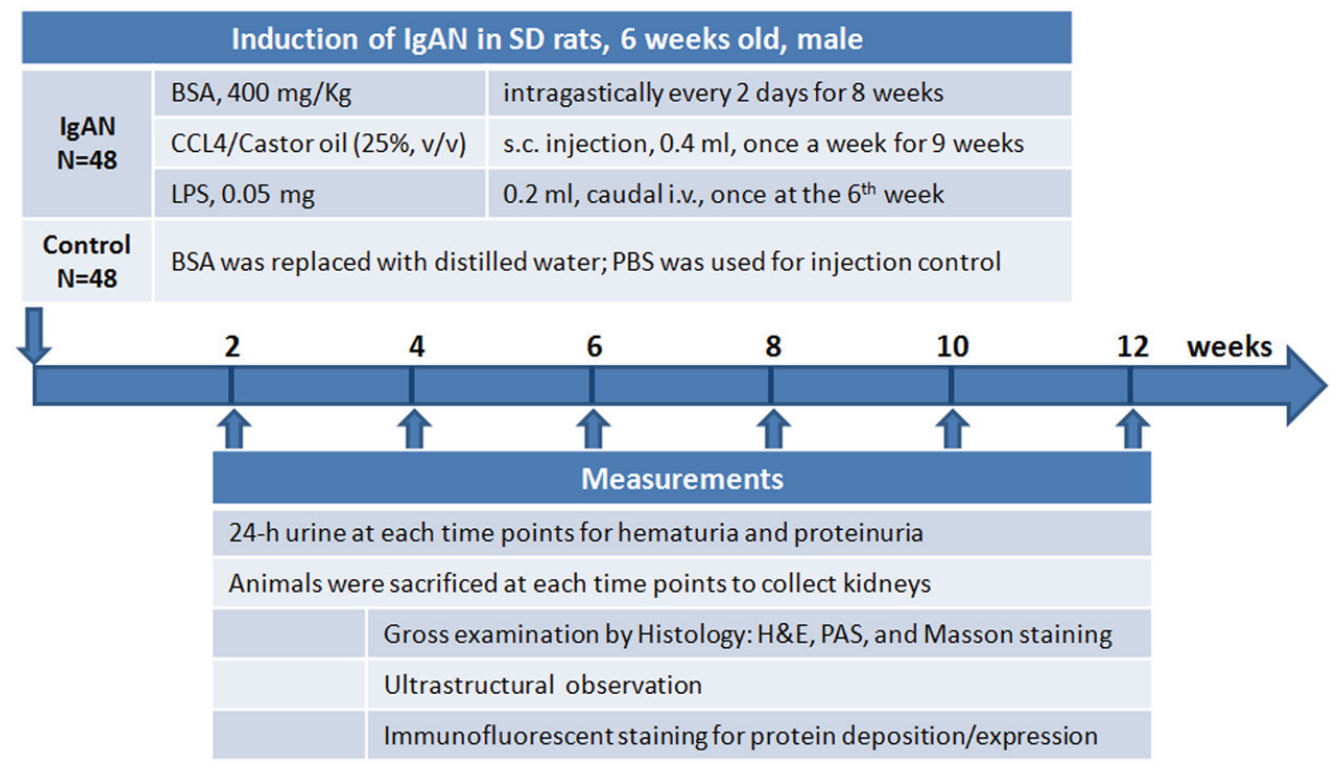

Fig. 1. Induction of IgAN in rats and timing of measurements. 
Table 1. Primers for real-time fluorescence quantitative PCR.

\begin{tabular}{lllc}
\hline Gene & & Primer Sequences & Length (bp) \\
\hline \multirow{2}{*}{ Nephrin } & forward & -CCCTCCGGGACCCTACTG & 82 \\
& reverse & -TCTGGGAGGATGGGATTGG & \\
Podocin & forward & -TGGAAGCTGAGGCACAAAGA & 97 \\
& foverse & -AGAATCTCAGCCGCCATCCT & 106 \\
Desmin & reverse & -GACGTGGAGCGTGACAACCT & 134 \\
& forward & -GGAAGGCAGCCAAGTTGTTC & \\
\hline
\end{tabular}

The main advantages of our modified model are: (i) oral administration of BSA with doubled dosage and elongated administration time was safer; (ii) as an immune adjuvant, only one intravenous injection of LPS at the $6^{\text {th }}$ week is less likely to have toxic effects; and (iii) the dosage of $\mathrm{CCl}_{4}$ was reduced to one third of the dosage used to induce hepatic fibrosis and a subcutaneous, rather than intraperitoneal, injection was used to minimize liver damage and reduce risk of peritoneal infection or animal death.

\section{Sample collection and preparation}

At the end of $2,4,6,8,10$, and 12 weeks, the 24-h urine was collected with metabolic cages, and urine color was observed. The presence of gross hematuria was recorded and Coomassie Brilliant Blue was used to measure the urinary protein. In addition, 8 rats in each group were sacrificed at different times and their kidneys were collected for histological examination. Each kidney was divided into 4 parts. The first one fourth was fixed in $40 \mathrm{~g} / 1$ formaldehyde, embedded in paraffin, cut into sections, and then stained by hematoxylin and eosin (H\&E), periodic acid-Schiff (PAS), or Masson's trichrome for light microscopy. The second quarter of kidney tissues was fixed in $25 \mathrm{ml} / \mathrm{l}$ glutaraldehyde + $20 \mathrm{ml} / 1$ paraformaldehyde followed by embedding, sectioning and staining with uranyl acetate and lead citrate for electron microscopy. The third portion was embedded in OTC and stored at $-70^{\circ} \mathrm{C}$ followed by frozen sectioning for immunofluorescence staining. The last quarter of kidney tissue was stored at $-70{ }^{\circ} \mathrm{C}$ for realtime quantitative fluorescence PCR.

\section{Measurement of $\operatorname{Ig} A$ deposition}

Direct immunofluorescence (FITC-conjugated rabbit anti-rats IgA antibody from Dako, USA) was used to visualize the $\operatorname{IgA}$ deposition in the glomeruli and was graded by a 5-stage semi-quantitative method (- to $++++)$ : $(-)$, no staining under low magnification and possible staining under high magnification; $(+)$, possible staining under low magnification and staining under high magnification; $(++)$, staining under low magnification and clear staining under high magnification; $(+++)$ clear staining under low magnification and bright staining under high magnification; $(++++)$, very intense staining under high magnification. In this study, most of the staining in the IAGN mode group was ++ to +++ .

Expression and distribution of nephrin, podocin and desmin in the glomeruli

Indirect immunofluorescence kits were used to detect the expression and distribution of nephrin, podocin, and desmin according to manufacturer's instructions (Abcam, UK). The primary antibodies were rabbit anti-rat nephrin antibody, rabbit anti-rat podocin antibody, and rabbit anti-rat desmin antibody (Abcam, UK). The secondary antibody was goat anti-rabbit antibody (Jackson, USA).

Blinded observers viewed the sections under a fluorescence microscope (AXIOPLAN 2, Carl Zeiss, Oberkochen, Germany). Representative photographs were captured using a digital camera for measuring the expression and distribution of nephrin, podocin, and desmin based on green fluorescence. A total of 5 glomeruli were selected from each section and the sum integrated optical density (IOD SUM) and sum area (area) were measured using Imagic-Pro Plus 6.0 software, followed by calculation of mean density (IOD SUM/area). The means of five glomeruli were used to quantify the expression of each protein. 
Table 2. Biochemical parameters of the control and IAGN rats at the end of week-12.

\begin{tabular}{lccc}
\hline Parameter & Controls & IgA nephropathy & $P$-value \\
\hline$A L T(\mathrm{U} / \mathrm{l})$ & $47.25 \pm 19.51$ & $59.48 \pm 20.82$ & 0.246 \\
$A S T(\mathrm{U} / \mathrm{l})$ & $103.61 \pm 25.95$ & $129.44 \pm 39.03$ & 0.141 \\
$A L B(\mathrm{~g} / \mathrm{l})$ & $36.76 \pm 1.49$ & $36.04 \pm 1.81$ & 0.398 \\
$T P(\mathrm{~g} / \mathrm{l})$ & $61.08 \pm 6.83$ & $62.59 \pm 3.96$ & 0.597 \\
$C H O L(\mathrm{mmol} / \mathrm{l})$ & $1.65 \pm 0.49$ & $1.52 \pm 0.20$ & 0.521 \\
$T G(\mathrm{mmol} / \mathrm{l})$ & $0.60 \pm 0.77$ & $0.70 \pm 0.15$ & 0.718 \\
$C r(\mu \mathrm{mol} / \mathrm{l})$ & $32.00 \pm 6.26$ & $34.88 \pm 11.90$ & 0.555 \\
$B U N(\mathrm{mmol} / \mathrm{l})$ & $6.81 \pm 0.72$ & $6.40 \pm 0.24$ & 0.161 \\
$C K-\mathrm{MB}(\mathrm{U} / \mathrm{l})$ & $1674.25 \pm 590.51$ & $1602.88 \pm 527.23$ & 0.802 \\
\hline
\end{tabular}

Comparisons were performed by Student's $t$-test. Data indicate means and standard deviations. Abbreviations: ALT, alanine amino transferase; AST, aspartate amino transferase; ALB, serum albumin; TP, total phosphate; $\mathrm{CHOL}$, total cholesterol; TG, triglycerides; $\mathrm{Cr}$, creatinine; BUN, blood urea nitrogen; CK-MB, creatinine kinase-myoglobin

Expression of nephrin, podocin, and desmin mRNAs in the renal cortex

RNA was extracted from the renal cortex after the kidney was separated into two parts along the sagittal plane. The cortex was separated along the medulla and stored directly at $-70{ }^{\circ} \mathrm{C}$ before real time PCR.

Real-time quantitative fluorescence PCR with SYBR Green was used to measure expression of nephrin, podocin, and desmin mRNAs in the renal cortex, with GAPDH as an internal reference. The gene sequences were identified in GeneBank for the design of specific primers (Table 1). Total RNA of the renal cortex was extracted using Trizol (Invitrogen, USA) according to the manufacturer's instructions. Then, $4 \mu \mathrm{l}$ of total RNA were subjected to reverse transcription with random primers, and M-MLV reverse transcriptase (Da'an Gene Co. Ltd., Guangzhou, China) in $20 \mu \mathrm{l}$ of reaction mixture using a PCR instrument (Model 9700, Applied Biosystems, city/state, USA). The reaction conditions were $37{ }^{\circ} \mathrm{C}$ for $1 \mathrm{~h}$ and then at $95^{\circ} \mathrm{C}$ for $3 \mathrm{~min}$. Then, $5 \mu \mathrm{l}$ of cDNA were added to the $50 \mu \mathrm{l}$ reaction mixture, followed by amplification in an automatic quantitative fluorescent PCR instrument (Model 7500, Applied Biosystems, USA). The PCR conditions were: predenaturation at $93{ }^{\circ} \mathrm{C}$ for $3 \mathrm{~min}, 40$ cycles of denaturation at $93{ }^{\circ} \mathrm{C}$ for $30 \mathrm{sec}$, annealing at $55^{\circ} \mathrm{C}$ for $45 \mathrm{sec}$, and extension at $72{ }^{\circ} \mathrm{C}$ for $45 \mathrm{sec}$. Expression of each target gene was normalized to that of GAPDH.

\section{Statistical analysis}

All data are expressed as means and standard deviations and statistical analysis was performed using
SPSS version 16.0. A $t$-test was used to compare two groups at different time points. Correlations were assessed by calculation of Pearson's correlation coefficient (R). A $p$-value less than 0.05 was considered statistically significant.

\section{Results}

Hematuria, proteinuria, urine red blood cell count and biochemical parameters

Control rats had no evidence of gross or microscopic hematuria throughout the experiment. IgAN rats had no evidence of hematuria before treatment, but all of these rats developed microscopic hematuria at week-6, and $60 \%$ of the IgAN rats ultimately developed gross hematuria (data not shown). Measurement of 9 biochemical parameters indicated no significant difference between the control and IgAN rats (Table 2, $p>0.05$ for all). The control and IgAN rats had similar levels of urinary protein before treatment, but at week-6, the IgAN rats had significantly more urinary protein, and their urinary protein continued to increase until week-12 (Table 3). The IgAN rats had significantly more urinary protein than control rats at week-6, $-8,-10$ and -12 $(p<0.001$ for all). Similarly, there were significantly more urinary red blood cells in IgAN rats at week-6 and the urinary red blood cell count in IgAN rats continued to increased to week-12 (Table 3). There were no animal deaths and no evidence of liver or cardiac damage during the entire study period. Taken together, these results indicate successful establishment of our IAGN model. 
Table 3. Daily urinary protein and daily urinary red blood cell count (mean \pm SD) in control and IAGN rats from week-2 to week-12.

\begin{tabular}{|c|c|c|c|c|c|c|c|}
\hline & \multirow[b]{2}{*}{ Groups } & \multicolumn{6}{|c|}{ Week } \\
\hline & & 2 & 4 & 6 & 8 & 10 & 12 \\
\hline $\begin{array}{l}\text { Urinary protein } \\
\text { (mg/day) }\end{array}$ & $\begin{array}{l}\text { Control } \\
\text { IgAN }\end{array}$ & $\begin{array}{l}2.72 \pm 1.04 \\
3.59 \pm 1.00\end{array}$ & $\begin{array}{l}3.95 \pm 0.97 \\
3.97 \pm 0.53\end{array}$ & $\begin{array}{c}4.28 \pm 0.73 \\
9.30 \pm 1.22^{*}\end{array}$ & $\begin{array}{c}4.47 \pm 0.61 \\
9.98 \pm 0.91^{*}\end{array}$ & $\begin{array}{c}5.10 \pm 0.52 \\
10.55 \pm 0.75^{*}\end{array}$ & $\begin{array}{c}5.08 \pm 0.55 \\
11.43 \pm 1.78^{*}\end{array}$ \\
\hline 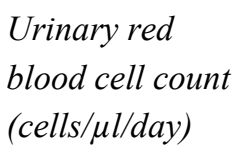 & $\begin{array}{l}\text { Control } \\
\operatorname{Ig} A N\end{array}$ & $\begin{array}{c}5.0 \pm 1.3 \\
5.2 \pm 1.28\end{array}$ & $\begin{array}{l}4.9 \pm 1.4 \\
5.6 \pm 1.3\end{array}$ & $\begin{array}{c}4.8 \pm 1.3 \\
196.3 \pm 11.7^{*}\end{array}$ & $\begin{array}{c}4.9 \pm 1.2 \\
499.4 \pm 27.3^{*}\end{array}$ & $\begin{array}{c}5.1 \pm 1.2 \\
851.5 \pm 20.6^{*}\end{array}$ & $\begin{array}{c}5.1 \pm 1.4 \\
901.1 \pm 20.2^{*}\end{array}$ \\
\hline
\end{tabular}

Comparisons were conducted by Student's $t$-test. Eight rats were in each group at each time point. $* \mathrm{P}<0.001$, compared to control group.

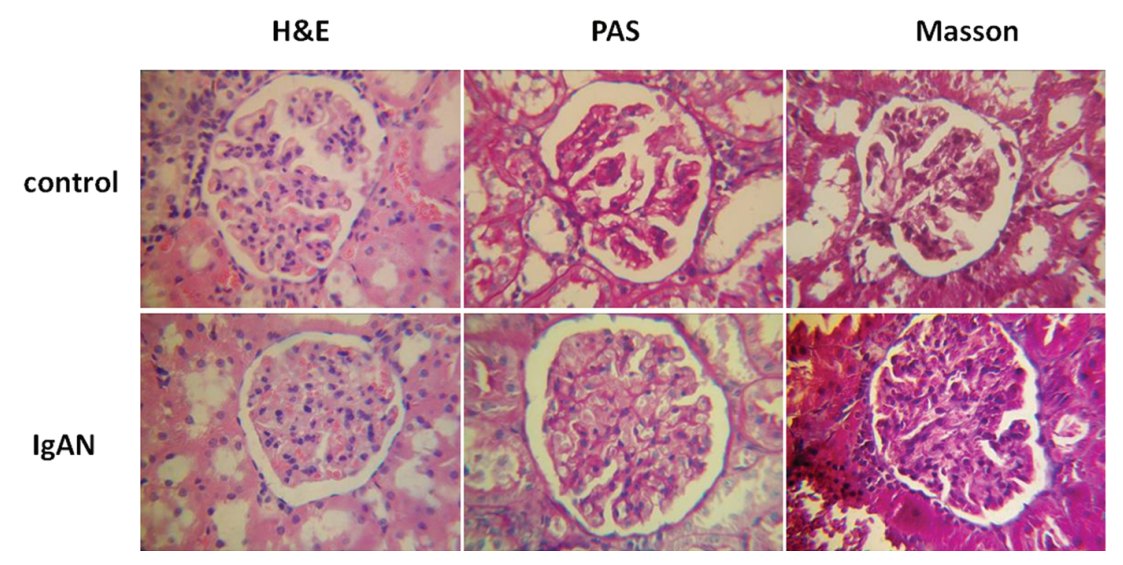

A
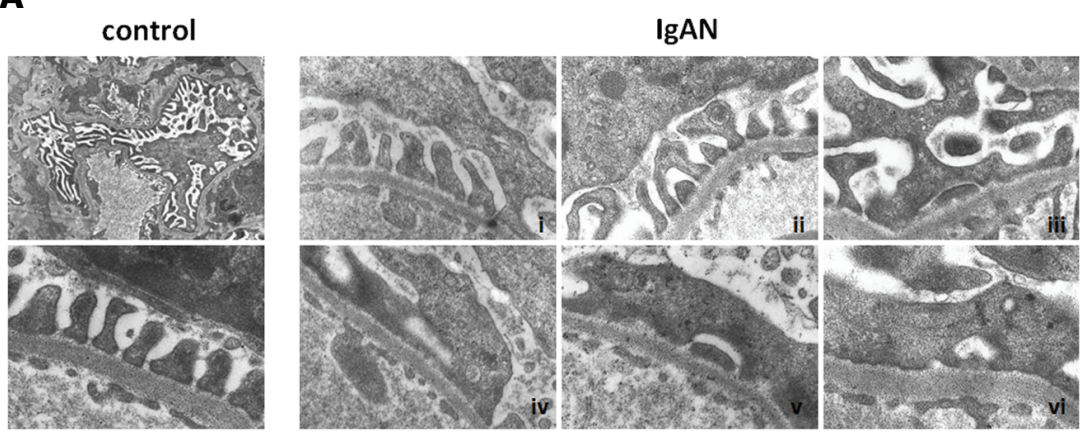

B

$\mathrm{i}, \mathrm{ii}, \mathrm{iii}, \mathrm{iv}, \mathrm{v}$ and vi present kidney images taken at the end of week $2,4,6,8,10$ and 12 , respectively
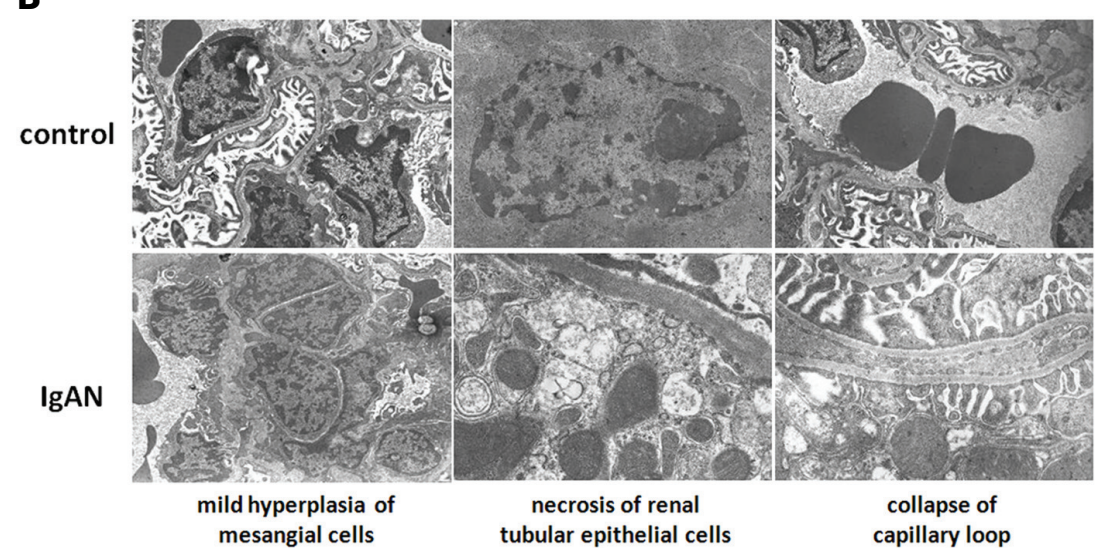

Fig. 2. Glomerular morphology of control and IgAN rats visualized by staining with hematoxylin and eosin (H\&E), periodic acid-Schiff (PAS), and Masson's trichrome at week-12.

Fig. 3. A. Transmission electron microscopy of the kidneys of control and IgAN rats $(\times 12000)$. B. Transmission electron microscopy of the kidneys of control rats and IgAN rats $(\times 5000)$. 

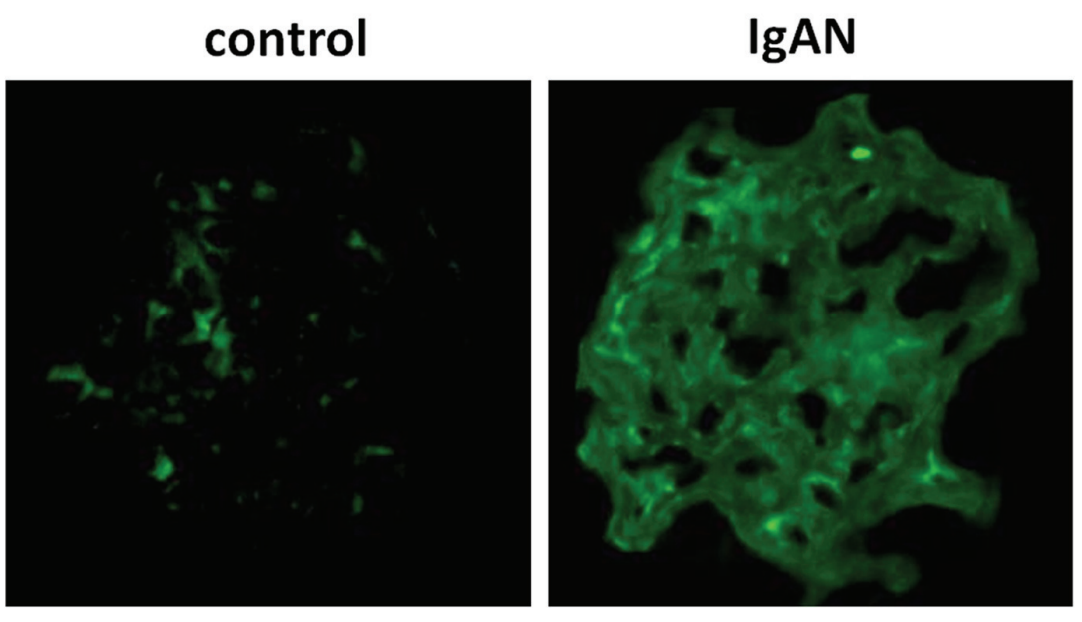

Fig. 4. Immunofluorescence staining for IgA in the glomeruli of control rats and IgAN rats at week $12(\times 200)$.

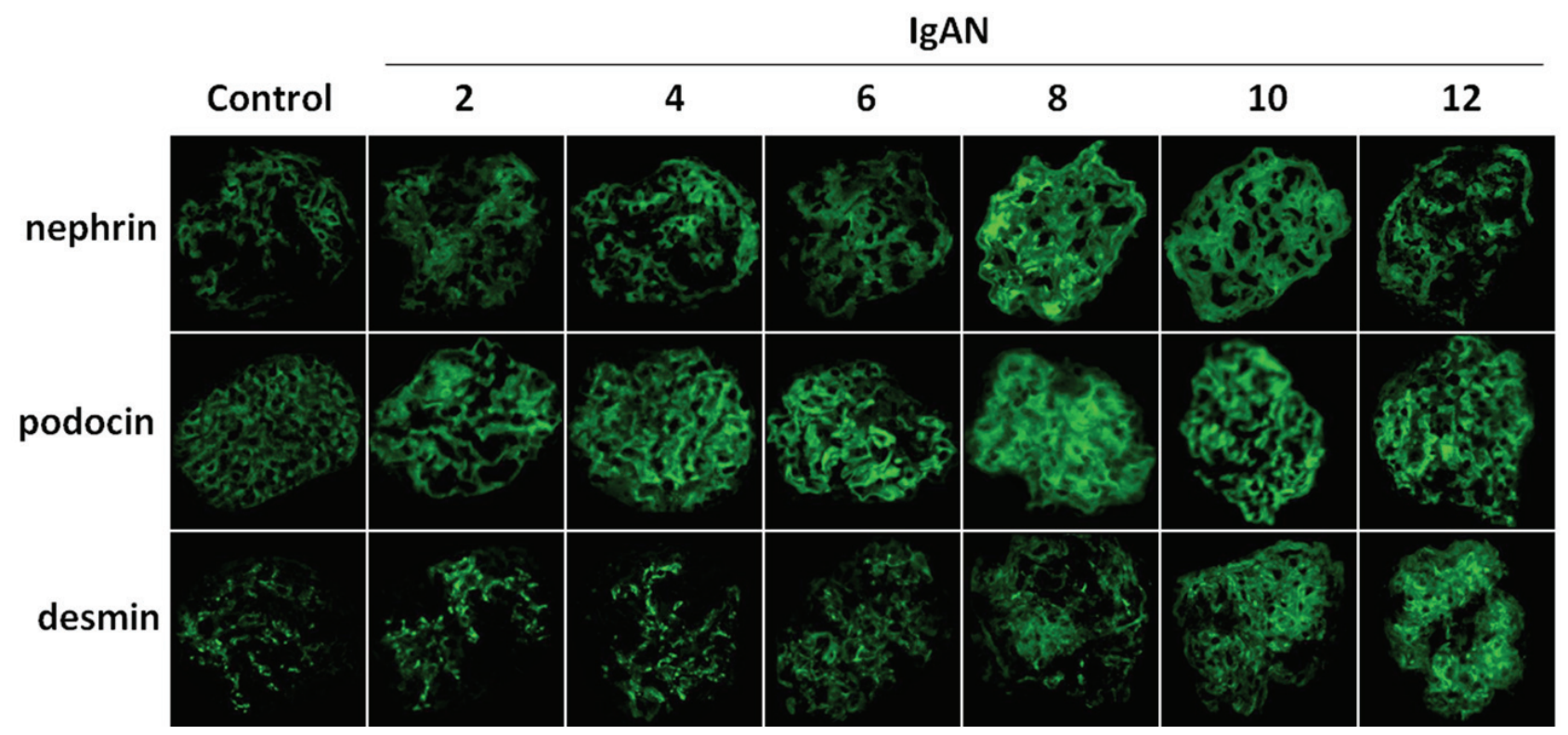

Fig. 5. Immunofluorescence staining of nephrin, podocin, and desmin in the glomeruli of control and IgAN rats $(\times 200)$.

\section{Light microscopy of the kidneys}

Light microscopy indicated that pathological changes were first evident in the IgAN rats at the end of week-2, and these became worse over time (Fig. 2). At the end of week-8, the pathological changes were very obvious and characterized by glomerular swelling, increased glomerular volume, increased number of cells in the glomeruli, and moderate to severe hyperplasia of mesangial matrix and cells. In some of the renal tubules, there was necrosis of epithelial cells and infiltration of inflammatory cells. These same features are evident in pathological specimens of humans with IgAN.

\section{Electron microscopy of the kidneys}

Electron microscopy indicated that IgAN rats developed deformation and partial fusion of foot processes at the end of week- 4 and that these changes became more evident over time (Fig. 3). The foot processes were flat at the end of week-6, and diffuse fusion of foot processes was obvious at the end of week10 and week-12 (Fig. 3), although effacement was not visible at this magnification. Again, these same features are evident in pathological specimens of humans with IgAN. In addition, IgAN rats developed mild hyperplasia of mesangial cells, collapse of the capillary loops, and necrosis of renal tubular epithelial cells (Fig. 3B).

\section{Immunofluorescence of $\operatorname{IgA}$}

Immunofluorescence staining of $\operatorname{IgA}$ indicated that control rats had very little deposition of IgA in the glomeruli, and the fluorescence intensity was scored as "(-)" to "(+)" for all samples (Fig. 4). In contrast, IgAN rats had significant mass- or granule-like green fluorescence which was scored as "++" to "+++" for all 
samples, although these images do not provide evidence for increased deposition in the thick loop region. Most of this fluorescence was in the glomeruli. Again, these results indicate successful establishment of IgAN.

Table 4. Relative concentration (mean \pm SD) of nephrin, podocin and desmin in the glomeruli of control and IAGN rats from week-2 to week-12.

\begin{tabular}{|c|c|c|c|c|c|c|c|}
\hline \multirow{2}{*}{\multicolumn{2}{|c|}{$\begin{array}{l}\text { Protein } \\
\text { expression }\end{array}$}} & \multicolumn{6}{|c|}{ Week } \\
\hline & & 2 & 4 & 6 & 8 & 10 & 12 \\
\hline \multirow[t]{2}{*}{ Nephrin } & Control & $0.095 \pm 0.017$ & $0.096 \pm 0.008$ & $0.097 \pm 0.006$ & $0.098 \pm 0.006$ & $0.099 \pm 0.006$ & $0.099 \pm 0.007$ \\
\hline & $\operatorname{Ig} A N$ & $0.104 \pm 0.006$ & $0.129 \pm 0.014^{* * *}$ & $0.148 \pm 0.017^{* * *}$ & $0.187 \pm 0.010^{* * *}$ & $0.148 \pm 0.010^{* * *}$ & $0.124 \pm 0.006^{* * *}$ \\
\hline \multirow[t]{2}{*}{ Podocin } & Control & $0.105 \pm 0.002$ & $0.104 \pm 0.016$ & $0.106 \pm 0.009$ & $0.103 \pm 0.011$ & $0.102 \pm 0.013$ & $0.102 \pm 0.004$ \\
\hline & $\operatorname{Ig} A N$ & $0.120 \pm 0.016^{*}$ & $0.123 \pm 0.019$ & $0.132 \pm 0.008^{* * *}$ & $0.154 \pm 0.007^{* * *}$ & $0.130 \pm 0.020^{* *}$ & $0.116 \pm 0.012^{*}$ \\
\hline \multirow[t]{2}{*}{ Desmin } & Control & $0.095 \pm 0.009$ & $0.098 \pm 0.007$ & $0.099 \pm 0.008$ & $0.100 \pm 0.004$ & $0.101 \pm 0.007$ & $0.101 \pm 0.007$ \\
\hline & $\operatorname{Ig} A N$ & $0.110 \pm 0.007^{* *}$ & $0.121 \pm 0.017^{* *}$ & $0.137 \pm 0.009^{* * *}$ & $0.149 \pm 0.007^{* * *}$ & $0.158 \pm 0.006^{* * *}$ & $0.170 \pm 0.008^{* * *}$ \\
\hline
\end{tabular}

The comparisons were conducted by Student's $t$-test. Eight rats were in each group at each time point. $* P<0.05$, ** $\mathrm{P}<0.01$, *** $\mathrm{P}<0.001$, compared to control group.

Glomerular expression of nephrin, podocin, and desmin proteins

Immunofluorescence staining for nephrin, podocin, and desmin indicated that the control rats had moderate expression of all three proteins, and that expression of each protein remained relatively constant over the 12 week experiment (Table 4). However, IgAN rats had increased expression of nephrin at week-4 $(p<0.001)$, maximal expression at week- 8 , and then a gradual decline (Fig. 5). Nephrin expression was significantly greater in IgAN rats than control rats from week-4 to week-12 ( $p<0.001$ for all time points). In control rats, nephrin had a continuous distribution along the capillary loops, but IgAN rats had much greater expression of nephrin at week-2, before the up-regulation (Fig. 5). Interestingly, changes in the expression and distribution of nephrin preceded the onset of proteinuria (Tables 3 and 4, Fig. 5).

IgAN rats had increased expression of podocin at week-2 $(p<0.05)$, maximal expression at week-8, and then a gradual decline (Fig. 5, Table 4). Podocin expression remained significantly higher than control rats at week-12 $(p<0.05)$. In control rats, podocin had a continuous distribution along the capillary loops, but IgAN rats had much greater expression of podocin at week-2. As with nephrin, changes in the expression and distribution of podocin preceded the onset of proteinuria (Tables 3 and 4, Fig. 5).

IgAN rats had increased expression of desmin at week-2 $(p<0.01)$ and desmin expression continued to increase up to week-12. As with nephrin and podocin, changes in the expression and distribution of desmin preceded the onset of proteinuria (Tables 3 and 4, Fig. 5).

Expression of nephrin, podocin, and desmin mRNAs in the renal cortex

IgAN rats had increased expression of nephrin and podocin mRNAs in the renal cortex at week-2 $(p<0.01$ for both), maximal expression at week- 8 , and then a decline to the level of control rats at week-12 (Table 5). IgAN rats had increased expression of desmin mRNA at week-8 $(p<0.01)$ and this remained higher than the control rats at week-12 $(p<0.05)$ (Table 5).

Correlation of expression of podocyte proteins and proteinuria

Finally, we used all of our data on IgAN rats $(n=48)$ and performed Pearson correlation analysis to assess the relationship between nephrin, podocin, and desmin proteins with 24-h urinary protein in the glomeruli of IgAN rats (Table 6). The results indicate that expression of nephrin, podocin, and desmin proteins were positively correlated with 24 -h urinary protein $(p<0.001$ for all). The relationship between nephrin, podocin and desmin mRNA in cortex of IgAN rats were also positively correlated with the 24-h urinary protein level $(p<0.001$ for all). 
Table 5. Relative expression of nephrin, podocin and desmin mRNAs (mean \pm SD) in the renal cortex of control and IAGN rats from week-2 to week-12.

\begin{tabular}{lllllll}
\hline \multirow{2}{*}{$\begin{array}{l}\text { mRNA } \\
\text { expression }\end{array}$} & \multicolumn{7}{c}{ Week } \\
\cline { 2 - 7 } & \multicolumn{1}{c}{$\mathbf{2}$} & \multicolumn{1}{c}{$\mathbf{4}$} & $\mathbf{6}$ & \multicolumn{1}{c}{$\mathbf{8}$} & \multicolumn{1}{c}{$\mathbf{1 0}$} & $\mathbf{1 2}$ \\
\hline \multirow{2}{*}{ Nephrin Control } & $0.176 \pm 0.021$ & $0.186 \pm 0.024$ & $0.186 \pm 0.029$ & $0.180 \pm 0.016$ & $0.182 \pm 0.011$ & $0.184 \pm 0.015$ \\
IgAN & $0.212 \pm 0.026^{* *}$ & $0.323 \pm 0.022^{* * *}$ & $0.479 \pm 0.052^{* * *}$ & $0.694 \pm 0.061^{* * *}$ & $0.225 \pm 0.018^{* * *}$ & $0.192 \pm 0.012$ \\
Podocin Control & $0.028 \pm 0.003$ & $0.027 \pm 0.002$ & $0.028 \pm 0.002$ & $0.027 \pm 0.003$ & $0.028 \pm 0.002$ & $0.028 \pm 0.002$ \\
IgAN & $0.043 \pm 0.002^{* * *}$ & $0.094 \pm 0.023^{* * *}$ & $0.138 \pm 0.005^{* * *}$ & $0.181 \pm 0.018^{* * *}$ & $0.122 \pm 0.009^{* * *}$ & $0.028 \pm 0.001$ \\
Desmin Control & $0.150 \pm 0.015$ & $0.154 \pm 0.020$ & $0.154 \pm 0.019$ & $0.150 \pm 0.009$ & $0.153 \pm 0.011$ & $0.154 \pm 0.018$ \\
\multicolumn{1}{c}{ IgAN } & $0.153 \pm 0.008$ & $0.153 \pm 0.012$ & $0.155 \pm 0.027$ & $0.333 \pm 0.083^{* * *}$ & $0.242 \pm 0.036^{* * *}$ & $0.177 \pm 0.016^{*}$ \\
\hline
\end{tabular}

The comparisons were conducted by Student's $t$-test. Eight rats were in each group at each time point. * $\mathrm{P}<0.05$, $* * \mathrm{P}<0.01$, *** $\mathrm{P}<0.001$, compared to control group.

Table 6. Pearson's correlation coefficients of the relationship of urinary protein, nephrin, podocin and desmin.

\begin{tabular}{lllll}
\hline mRNA & $\begin{array}{l}\text { Urine } \\
\text { protein }\end{array}$ & Nephrin Podocin Desmin \\
\hline Urine protein & - & $0.708^{*}$ & $0.460^{*}$ & $0.864^{*}$ \\
Nephrin & $0.460^{*}$ & $0.813^{*}$ & - & - \\
Podocin & $0.577^{*}$ & - & $0.763^{*}$ & - \\
Desmin & $0.527^{*}$ & - & - & $0.502^{*}$ \\
\hline
\end{tabular}

Data were expressed by Pearson's correlation coefficient. $* \mathrm{P}<0.001$, correlation coefficient was significantly different from zero.

\section{Discussion}

We used an established methodology to create rats with IgAN and then used this model to assess the roles of 3 podocyte proteins - nephrin, podocin, and desmin - in the pathogenesis of IgAN. We found the expression and distribution of nephrin preceded the onset of proteinuria and the expression of nephrin, podocin, and desmin proteins were positively correlated with 24-h urinary protein.

Interestingly, many of our model rats developed gross hematuria, yet had no evidence of segmental lesions, in contrast to the situation in humans. This may have been due to inherent biological differences of rats and humans or because the rapid induction of IgAN in our model did not allow time for the development of these pathological changes. Previous studies of congenital and hereditary kidney diseases, acquired kidney diseases, and animal models of kidney diseases have identified changes in numerous podocyte-associated molecules (Luimula et al. 2000, Forbes et al. 2002, Guan et al. 2002, Luimula et al. 2002, Koop et al. 2003, Guan et al. 2004). These studies indicate that the SD complex appears to be regulated by nephrin, podocin, desmin, and $\mathrm{CD} 2$ associated protein (CD2AP) via their interactions with the podocyte cytoskeleton. However, there is currently no consensus on the role of these podocyteassociated proteins in the pathogenesis of proteinuria and kidney diseases (Ortmann et al. 2004, Jalanko 2003). Although the molecular mechanisms underlying proteinuria are not fully understood, animal and clinical studies suggest that changes in the expression and distribution of podocyte-associated molecules may damage the structure and function of the podocyte SD, and thereby disrupt glomerular filtration and cause proteinuria (Jalanko 2003, Ortmann et al. 2004, Li et al. 2008, Xu et al. 2010).

Previous studies of IgAN have produced conflicting results regarding the expression and distribution of podocyte-associated molecules. Patrakka et al. (2001) employed immunohistochemistry and in situ hybridization to measure expression of nephrin in the kidneys of patients with IgAN and reported no apparent changes. However, Gagliardini et al. (2003), using the same methods, reported up-regulation of nephrin. Koop et al. (2003) used immunohistochemistry and real-time quantitative PCR to measure expression of nephrin and podocin in the kidneys of IgAN patients and reported no apparent changes. Mao et al. (2006) performed immunohistochemistry, immunofluorescence microscopy, and real-time quantitative PCR to investigate the kidneys of children with IgAN. They reported that desmin protein was down-regulated, but that desmin 
mRNA, podocin protein, and podocin mRNAs all had stable expression. They also reported that nephrin expression was positively associated with serum albumin in children with IgAN. Taken together, these studies seem to indicate an inconsistent relationship between disrupted expression of these proteins and IgAN. However, none of these studies investigated the association between proteinuria in IgAN with disrupted expression of podocyte-associated proteins and with pathological changes in foot process morphology.

The immunofluorescence results of the present study provide semi-quantitative evidence that changes in the expression and distribution of nephrin, podocin, and desmin preceded the deformation of foot processes and proteinuria, and that expression of these proteins were positively correlated with the concentration of urinary protein. These findings support our hypothesis that alterations in the expression and distribution of podocyteassociated proteins contribute to proteinuria in IgAN. Changes in the expression of podocyte proteins may disrupt the structure and function of podocyte SDs, promote the rearrangement of the podocyte cytoskeleton, and thereby disrupt glomerular filtration and cause proteinuria (Li et al. 2008). In addition, we also observed increased levels of glomerular nephrin and podocin in IgAN rats and that these changes occurred at nearly the same time as the increased expression (week-2). Guan et al. (2004) previously reported that abnormal distribution of nephrin and podocin preceded changes in the expression of both proteins in rats with polyarteritis nodosa (PAN), and speculated that abnormal distribution of these proteins was due to their elevated expression.

In our IgAN model, podocin expression changed before nephrin expression, consistent with previous reports (Schwarz et al. 2001, Guan et al. 2004, Xin et al. 2006). This finding suggests that up-regulation of podocin might be an initial process in the pathogenesis of proteinuria, and that podocin, as a component of the podocyte $\mathrm{SD}$, plays a crucial role in maintaining the stability of nephrin in the SD complex (Schwarz et al. 2001). Our results also indicated that up-regulation of nephrin and podocin mRNAs occurred before upregulation of desmin mRNA. Thus, the initial upregulation of nephrin and podocin may change the SD complex and induce rearrangement of the podocyte cytoskeleton (Xin et al. 2006), resulting in alteration of desmin expression. The changes that we observed may result from a "chain reaction" that is triggered by podocyte injury, but we have no direct evidence for this at present. Fan et al. (2005) previously reported that the interactions and associations of these proteins were dynamic and complex.

In our $\operatorname{IgAN}$ rats, expression of nephrin and podocin were up-regulated early and then decreased. This up-regulation may be compensatory and the downregulation may be a result of podocyte injury, as previously suggested by Koop et al. (2003). Several lines of evidence support this hypothesis. Podocytes are mature cells which are well differentiated and have limited ability to proliferate (Hernandez et al. 2004). Thus, when they are injured, the expression and activities of cyclindependent kinase inhibitors (e.g. P21 and P27) increase, and podocytes have limited ability to compensate for this injury (Wang et al. 2004). Thus, in the present study, the increased expression of podocyte-associated proteins is due to increased synthesis within each cell, not from podocyte proliferation. Xin et al. (2006) and Peng et al. (2009) reported increased expression of nephrin and podocin in the kidneys of rats with adriamycin (ADR)induced cadiomyopathy, but that the number of podocytes remained unchanged. Thus, podocytes may have a mechanism for protection against injury at the early stages of IgAN, but this mechanism may not be able to compensate for extensive injury. The mechanisms involved in the compensation of podocyte injury and the effects of compensation on renal function are still poorly understood and require further studies.

Our results also indicate that nephrin and podocin had abnormal cellular distributions in IgAN rats. Thus, the increased production of podocyte-associated proteins did not result in their accumulation in the plasma membrane, but was presumably due to accumulation in other organelles, such as endoplasmic reticulum. We hypothesize that these up-regulated proteins have altered biological function, leading to an unstable SD complex and an interruption of the connection between these proteins and the cytoskeleton, culminating in proteinuria (Roselli et al. 2004).

Our results also indicated that some of the changes in protein expression in $\operatorname{IgAN}$ rats were inconsistent with the changes in mRNA expression: (i) at week-2, nephrin and podocin mRNAs were markedly upregulated, but the proteins were up-regulated at week-4; (ii) at week-12, nephrin and podocin mRNAs of IgAN rats were similar to those of control rats, but the proteins were significantly higher in model than control rats; (iii) at week-2, desmin mRNA expression was upregulated and increased progressively up to week-12, but 
expression of desmin protein was maximal at week- 8 , and then declined. Taken together, these results indicate that dysregulation of the expression of these genes is due to translational and post-translational effects. Luimula et al. (2002) and Koop et al. (2003) also reported disparate changes in the expression of nephrin and podocin proteins and mRNAs in rats with PAN. The mechanism underlying the dysregulation of these genes should be further investigated.

In conclusion, our study of a rat model of $\operatorname{IgAN}$ indicated that changes in the expression and distribution of nephrin, podocin, and desmin precede foot process fusion and proteinuria. Although our results do not prove a causal relationship between these events, our results and those of previous studies suggest that disruption in the expression and distribution of these proteins is a crucial event in the pathogenesis of IgAN.

\section{Conflict of Interest}

There is no conflict of interest.

\section{Acknowledgements}

This work was supported by Science and Technology Planning Project of Guangdong Province (No. 2011B031800260), National Innovation Training Program Project for College Students (No. 101055838), Medical Scientific Research Fund of Guangdong Province (No. B2012092) and Baili Scientific Research Fund for Pediatrics of China (No. HT1203010).

\section{References}

BARRATT J, FEEHALLY J: IgA Nephropathy. J Am Soc Nephrol 16: 2088-2097, 2005.

CAI GY, CHEN XM: Immunoglobulin A nephropathy in China: progress and challenges. Am J Nephrol 30: 268-273, 2009.

EMANCIPATOR SN: Animal models of IgA nephropathy. Curr Protoc Immunol Unit 15.11, 2001.

EMANCIPATOR SN: Prospects and perspectives on IgA nephropathy from animal models. Contrib Nephrol 169: 126152, 2011.

FAN QF, DING J, XIN Y, GUAN N, ZHANG JJ: Study on molecular effect and interaction among podocyte molecules by gene knockdown. (in Chinese) Chin J Nephrol 21: 593-599, 2005.

FORBES JM, BONNET F, RUSSO LM, BURNS WC, CAO Z, CANDIDO R, KAWACHI H, ALLEN TJ, COOPER ME, JERUMS G, OSICKA TM: Modulation of nephrin in the diabetic kidney: association with systemic hypertension and increasing albuminuria. J Hypertens 20: 985-992, 2002.

GAGLIARDINI E, BENIGNI A, TOMASONI S, ABBATE M, KALLURI R, REMUZZI G: Targeted downregulation of extracellular nephrin in human IgA nephropathy. Am J Nephrol 23: 277-286, 2003.

GUAN N, DING J, ZHANG J, YANG J: Expression of nephrin, podocin, $\alpha$-actinin and WT1 in children with nephrotic syndrome. Pediatr Nephrol 18: 1122-1127, 2003.

GUAN N, DENG JH, DING J, ZHANG JJ, YANG JY: Relationship between expression of nephrin, podocin and $\alpha$-actinin with proteinuria in puromycin aminonucleoside nephrosis rats. (in Chinese) Chin J Nephrol 20: 2632, 2004.

HERNANDEZ R, TERUEL T, DE ALVARO C, LORENZO M: Rosiglitazone ameliorates insulin resistance in brown adipocytes of Wistar rats by impairing TNF-alpha induction of p38 and p42/p44 mitogen-activated protein kinases. Diabetologia 47: 1615-1624, 2004.

JALANKO H: Pathogenesis of proteinuria: lessons learned from nephrin and podocin. Pediatr Nephrol 18: 487-491, 2003.

KIRYLUK K, JULIAN BA, WYATT RJ, SCOLARI F, ZHANG H, NOVAK J, GHARAVI AG: Genetic studies of IgA nephropathy: past, present, and future. Pediatr Nephrol 25: 2257-2268, 2010.

KOOP K, EIKMANS M, BAELDE HJ, KAWACHI H, DE HEER E, PAUL LC, BRUIJN JA: Expression of podocyteassociated molecules in acquired human kidney diseases. J Am Soc Nephrol 14: 2063-2071, 2003.

LAI KN, LEUNG JC, CHAN LY, SALEEM MA, MATHIESON PW, TAM KY, XIAO J, LAI FM, TANG SC: Podocyte injury induced by mesangial-derived cytokines in IgA nephropathy. Nephrol Dial Transplant 24: 62$72,2009$. 
LI Y, KANG YS, DAI C, KISS LP, WEN X, LIU Y: Epithelial-to-mesenchymal transition is a potential pathway leading to podocyte dysfunction and proteinuria. Am J Pathol 72: 299-308, 2008.

LUIMULA P, AHOLA H, WANG SX, SOLIN ML, AALTONEN P, TIKKANEN I, KERJASCHKI D, HOLTHÖFER H: Nephrin in experimental glomerular disease. Kidney Int 58: 1461-1468, 2000.

LUIMULA P, SANDSTRÖM N, NOVIKOV D, HOLTHÖFER H: Podocyte-associated molecules in puromycin aminonucleoside nephrosis of the rat. Lab Invest 82: 713-718, 2002.

MAO J, ZHANG Y, DU L, DAI Y, YANG C, LIANG L: Expression profile of nephrin, podocin, and CD2AP in Chinese children with MCNS and IgA nephropathy. Pediatr Nephrol 21: 1666-1675, 2006.

MUNDEL P, SHANKLAND SJ: Podocyte biology and response to injury. J Am Soc Nephrol 13: 3005-3015, 2002.

ORTMANN J, AMANN K, BRANDES RP, KRETZLER M, MUNTER K, PAREKH N, TRAUPE T, LANGE M, MATTMANN T, BARTON M: Role of podocytes for reversal of glomerulosclerosis and proteinuria in the aging kidney after endothelin inhibition. Hypertension 44: 974-981, 2004.

PATRAKKA J, RUOTSALAINEN V, KETOLA I, HOLMBERG C, HEIKINHEIMO M, TRYGGVASON K, JALANKO H: Expression of nephrin in pediatric kidney diseases. J Am Soc Nephrol 12: 289-296, 2001.

PENG W, LIU ZR: Comparison of two rat models of IgA nephropathy. (in Chinese) J South Med Univ 28: 1842-1845, 2008.

PENG YQ, MO Y, JIANG XY, ZHANG QL, CHEN SM: Expression and significance of nephrin and CD2AP in adriamycin-induced nephrotic rats. (in Chinese) J Sun Yatsen Univ (Med Sci) 31: 15-25, 2009.

REICH HN, TROYANOV S, SCHOLEY JW, CATTRAN DC: Remission of proteinuria improves prognosis in IgA nephropathy. J Am Soc Nephrol 18: 3177-3183, 2007.

RIFAI A, SMALL PA Jr, TEAGUE PO, AYOUB EM: Experimental IgA nephropathy. J Exp Med 150: 1161-1173, 1979.

ROSELLI S, MOUTKINE I, GRIBOUVAL O, BENMERAH A, ANTIGNAC C: Plasma membrane targeting of podocin through the classical exocytic pathway: effect of NPHS2 mutations. Traffic 5: 37-44, 2004.

SCHWARZ K, SIMONS M, REISER J, SALEEM MA, FAUL C, KRIZ W, SHAW AS, HOLZMAN LB, MUNDEL P: Podocin, a raft-associated component of the glomerular slit diaphragm, interacts with CD2AP and nephrin. J Clin Invest 108: 1621-1629, 2001.

SZETO CC, LAI KB, CHOW KM, SZETO CY, YIP TW, WOO KS, LI PK, LAI FM: Messenger RNA expression of glomerular podocyte markers in the urinary sediment of acquired proteinuric disease. Clin Chim Acta 361: 182-190, 2005.

TANG Y, LOU TQ, CHENG CL: The modification of laboratory IgA nephropathy model. J Zhongshan Univ (Med) 27: 184-187, 2006.

WANG S, KIM JH, MOON KC, HONG HK, LEE HS: Cell-cycle mechanisms involved in podocyte proliferation in cellular lesion of focal segmental glomerulosclerosis. Am J Kidney Dis 43: 19-27, 2004.

XIN Y, DING J, FAN QF, GUAN N: Increased expression of podocyte molecules might cause proteinuria in adriamycin-induced nephrotic rats. (in Chinese) Chin J Nephrol 22: 27-32, 2006.

XU L, YANG HC, HAO CM, LIN ST, GU Y, MA J: Podocyte number predicts progression of proteinuria in IgA nephropathy. Mod Pathol 23: 1241-1250, 2010. 